\title{
Kajian Geometri Jalan Tambang berdasarkan Aashto dan Kepmen No 1827/K/30/Mem/2018 pada Penambangan Andesit di PT XYZ, Kecamatan Rumpin, Kabupaten Bogor, Provinsi Jawa Barat
}

\author{
Muhammad Dwi Nanda* \\ Prodi Teknik Pertambangan, Fakultas Teknik, Universitas Islam \\ Bandung, Indonesia. \\ *muhdwinanda13@gmail.com
}

\begin{abstract}
This study discusses the influence of mining road conditions on the circulation time of the conveyance and the work efficiency of the loading equipment. In this study, the study of mine road geometry refers to the theory of AASHTO (American Association of State Highway and Transportation Officials) in 1993 and Ministerial Decree No. 1827/K/30/MEM/2018. The geometry of the road includes the width of the road in straight conditions, the width of the road in bend conditions, the radius of the bend, the road slope (Grade), cross slope (Cross slope), superelevation, the actual rimpull calculation which is compared with theoretical calculations based on AASHTO theory (American Association of State Highways and Transportation Officials).The study of road geometry is associated with the production of digging and loading equipment to increase andesite mining production. The production observation area is carried out on the work front which is on bench 9 to the hopper, the results of observations in actual conditions are calculated and then compared with the results of theoretical calculations. In the observation area, the width of the straight road has varying values ranging from 8.12 meters to 21.60 meters, then the width of the road with bend conditions has a road width of 9.12 meters to 17.94 meters, while the slope of the road has a varying slope. ranging from $3.49 \%-38.39 \%$ with rimpull available on conveyances from gears 1 - 7. From the results of the actual production calculation, it is less than optimal because there are several obstacles in terms of road geometry that do not meet the standards so that the transportation equipment cycle time is longer which will affect production, therefore to increase production, mining road geometry improvements are made for road segments that does not meet the standards of the theory of AASHTO (American Association of State Highway and Transportation Officials) and Kepmen No. 1827/K/30/MEM/2018.
\end{abstract}

Keywords: AASHTO, Circular Time, Road Geometry.

Abstrak. Pada penelitian ini membahas terkait pengaruh kondisi jalan tambang terhadap waktu edar alat angkut dan efisiensi kerja alat muat. Pada penelitian ini untuk kajian geometri jalan tambang mengacu pada AASHTO (American Association of State Highway and Transportation Officials) tahun 1993 dan Kepmen No. 1827/K/30/MEM/2018. Geometri jalan meliputi lebar jalan kondisi lurus, lebar jalan kondisi tikungan, jari-jari tikungan, kemiringan jalan (Grade), kemiringan melintang (Cross slope), superelevasi, perhitungan rimpull secara aktual yang dibandingkan dengan perhitungan secara teoritis berdasarkan AASHTO (American Association of State Highway and Transportation Officials). Kajian geometri jalan dikaitkan dengan produksi alat gali-muat dan alat angkut untuk meningkatkan produksi penambangan andesit. Area pengamatan produksi dilakukan pada front kerja yang berada di bench 9 sampai hopper, hasil dari pengamatan dalam kondisi aktual dihitung lalu dibandingkan dengan hasil perhitungan secara teoritis. Pada area pengamatan kondisi lebar jalan lurus memiliki nilai bervariasi mulai dari 8,12 meter sampai 21,60 meter, lalu untuk lebar jalan dengan kondisi tikungan memiliki lebar jalan sebesar 9,12 meter sampai 17,94 meter, sedangkan untuk kemiringan jalan memiliki kemiringan bervariasi mulai dari 3,49\% - 38,39\%. Dengan rimpull tersedia pada alat angkut dari gear 1 - 7. Dari hasil perhitungan secara aktual tersebut kurang maksimal karena adanya beberapa hambatan dari segi geometri jalan yang belum memenuhi standar sehingga waktu edar alat angkut semakin lama yang nantinya akan berpengaruh terhadap produksi, oleh karena itu untuk meningkatkan produksi dilakukan perbaikan geometri jalan tambang untuk segmen jalan yang belum memenuhi standar dari AASHTO (American Association of State Highway and Transportation Officials) dan Kepmen No. 1827/K/30/MEM/2018.

Kata Kunci: AASHTO, Waktu edar, Geometri Jalan. 


\section{A. Pendahuluan}

PT XYZ merupakan suatu perusahaan yang bergerak di sektor industri pertambangan yang memproduksi bahan galian andesit, terletak di Kecamatan Rumpin, Kabupaten Bogor, Provinsi Jawa Barat. Dalam melakukan kegiatan penambangan perusahaan menggunakan alat gali-muat Kobelco SK-330 dan alat angkut menggunakan Dump Truck Tonly TL855BR.

Pada lokasi penelitian yang menjadi permasalahan adalah target produksi yang tidak tercapai dan salah satu faktor yang berpengaruh adalah geometri jalan. Keadaan di daerah penelitian ada beberapa geometri jalan yang belum sesuai dengan standar yang telah ditetapkan seperti pada lebar jalan, dimana alat angkut tidak dapat berpapasan langsung dan juga kemiringan jalan yang terlalu curam, sehingga dapat menimbulkan alat angkut tidak dapat bekerja secara optimal dan berpengaruh terhadap waktu edar alat tersebut. Semakin lama waktu edar alat angkut maka produksi akan semakin menurun.

Dalam melakukan kajian jalan tambang untuk meningkatkan produksi penambangan batu andesit mengacu pada AASHTO (American Association of State Highway and Transportation Officials) dan Kepmen No. 1827/K/30/MEM/2018 mengenai standar yang diterapkan pada jalan tambang.

Berdasarkan latar belakang tersebut, maka didapatkan perumusan masalah pada penelitian ini adalah : "Kondisi geomeri jalan tambang aktual yang tidak sesuai dengan kesesuaian Kepmen No. 1827/K/30/MEM/2018 dan AASHTO”.

Tujuan dalam penelitian ini adalah mengetahui kondisi geometri jalan tambang aktual dan kesesuaiannya dengan standar AASHTO dan Kepmen No. 1827/K/30/MEM/2018.

\section{B. Metodologi Penelitian}

Metode penelitian yang digunakan dalam skripsi ini yaitu dengan cara pengambilan data dilapangan serta pengolahan data sehingga dapat dihasilkan suatu analisis dari kegiatan pengukuran, dan pengolahan. Data yang didapatkan dari metode yang dilakukan antara lain :

1. Pengambilan Data

a. Metode Primer

Data primer merupakan data yang didapatkan secara langsung waktu kerja, waktu hambatan, waktu edar, geometri jalan tambang, kecepatan alat angkut, Fill Factor, Swell Factor dan target produksi perusahaan.

b. Metode Sekunder

Data sekunder adalah data yang tidak diambil langsung di lapangan diantaranya spesifikasi alat muat dan alat angkut, curah hujan, peta administrasi, dan peta topografi.

2. Pengolahan Data

Pengolahan data geometri jalan seperti lebar jalan lurus, lebar jalan kondisi tikungan, kemiringan jalan, jari-jari tikungan, superelevasi, dan rimpull dilakukan perhitungan berdasarkan American Association of State Highway and Transportation Officials (AASHTO). Selanjutnya dilanjutkan perhitungan pada data yang didapatkan seperti, efisiensi kerja, produktivitas dan produksi alat muat dan alat angkut serta Match Factor.

3. Analisis hasil pengolahan data menggunakan metode komparasi antara geometri jalan secara aktual dengan hasil perhitungan berdasarkan AASHTO dan standar Kepmen No. 1827/K/30/MEM/2018.

Untuk membantu dalam perhitungan,analisis serta pembahasan diperlukan beberapa teori penunjang yang dibutuhkan sebagai berikut:

Jalan Tambang merupakan jalan yang terdapat pada area pertambangan dan/atau area proyek yang digunakan dan dilalui oleh alat pemindah tanah mekanis dan unit penunjang lainnya dalam kegiatan pengangkutan tanah penutup, bahan galian tambang, dan kegiatan penunjang pertambangan (Kepmen ESDM 1827 K,2018).

Salah satu hal yang menyebabkan tidak tercapainya target produksi adalah kondisi jalan angkut. Beberapa faktor yang mempengaruhi alat angkut tidak dapat beroperasi secara optimal antara lain kondisi jalan angkut yang sempit sehingga ketika alat angkut berpapasan salah satu alat angkut harus berhenti, terdapat tanjakan yang curam sehingga alat angkut harus mengurangi 
kecepatan untuk bisa mengatasi tanjakan, kondisi jalan yang bergelombang sehingga pada saat pengangkutan banyak material yang berserakan, perlu dilakukan evaluasi teknis mengenai kondisi geometri jalan angkut yang tujuannya adalah untuk memperlancar poses pengangkutan dan juga memberikan rasa aman bagi operator alat angkut ketika melewati jalan tersebut. Baiknya kondisi jalan akan mempertinggi nilai efisiensi kerja alat dan waktu siklus alat angkut lebih cepat serta mempertinggi tingkat keamanan dari operator sehingga akan meningkatkan produktivitas. (Oktafian, 2018)

Oleh karena itu diperlukan penentuan geometri jalan tambang yang sesuai dengan dimensi alat angkut agar dapat beroprasi secara optimal.

1. Lebar Jalan Lurus

Lebar jalan angkut tambang mempertimbangkan alat angkut terbesar yang melintasi jalan tersebut paling kurang tiga setengah kali lebar alat angkut untuk dua arah dan dua kali lebar alat angkut untuk jalan tambang satu arah. Pada jalan lurus di tepi kiri dan tepi kanan harus ditambah dengan setengah lebar alat angkut.

$$
\mathrm{L}_{\min }=\mathbf{n} \cdot \mathrm{Wt}+(\mathbf{n}+\mathbf{1})(0,5 \times \mathrm{Wt})
$$

Keterangan:

Lmin = Lebar jalan angkut minimum (m)

$\mathrm{n} \quad=$ Jumlah jalur

Wt $=$ Lebar alat angkut $(\mathrm{m})$

2. Lebar Jalan Kondisi Tikungan

Lebar jalan angkut pada tikungan selalu dibuat lebih besar dari pada jalan lurus. Hal ini dimaksudkan untuk mengantisipasi adanya penyimpangan lebar alat angkut yang disebabkan oleh sudut yang dibentuk oleh roda depan dengan badan truk saat melintasi tikungan. Untuk jalur ganda, lebar jalan minimum pada tikungan dihitung berdasarkan pada Lebar jejak roda, Lebar juntai atau tonjolan (overhang) alat angkut bagian depan dan belakang pada saat membelok, Jarak antar alat angkut saat bersimpangan, Jarak jalan angkut terhadap tepi jalan (Sari, et al, 2020).

3. Jari-Jari Tikungan dan Superelevasi

Pada saat kendaraan melalui tikungan atau belokan dengan kecepatan tertentu atau menerima gaya sentrifugal yang menyebabkan kendaraan tidak stabil, untuk mengimbangi gaya sentrifugal tersebut perlu dibuat suatu kemiringan melintang ke arah titik pusat tikungan yang disebut superelevasi. (Maulana 2018).

4. Kemiringan Jalan (Grade)

Kemiringan jalan dapat terjadi karena adanya perbedaan elevasi pada kontur, sehingga terdapat jalan yang menanjak maupun menurun sehinga adanya kemiringan. Kemiringan jalan ini akan berhubungan langsung dengan kemampuan suatu alat angkut, saat pengereman maupun saat mengatasi tanjakan. (Prodjosumarto, 1993).

$$
\text { Kemiringan }(\%)=\frac{\Delta h}{\Delta x} \times 100 \%
$$

Keterangan
$" \Delta \mathrm{h} " \quad=$ Beda tinggi antara dua titik segmen yang diukur (meter)
$" \Delta \mathrm{x} " \quad$ = Jarak antara dua titik segmen jalan yang diukur (meter)

5. Cross Slope

Angka cross slope pada jalan angkut dinyatakan dalam perbandingan jarak vertikal dan horizontal dengan satuan $\mathrm{mm} / \mathrm{m}$. Pada konstruksi jalan angkut surface mining, besarnya cross slope yang dianjurkan mempunyai ketebalan sekitar $20 \mathrm{~mm}$ hingga $40 \mathrm{~mm}$ untuk setiap meter. (Azwari, 2015). 


\section{Hasil Penelitian dan Pembahasan}

\section{Geometri Jalan}

Berdasarkan hasil penelitian yang dilakukan kondisi geometri jalan tambang yang digunakan dibagi kedalam 32 segmen jalan dengan Panjang jalan angkut dari Hopper ke Loading Point yang berada di bench 9 sejauh \pm 1066 meter. Hasil dari pembagian segmen jalan tersebut dibandingkan dengan Kepmen No. 1827/K/30/MEM/2018 dan AASHTO untuk mengevaluasi kesesuaian geometri jalan tambang yang digunakan. Sketsa pembagian segmen jalan dapat dilihat pada Gambar 1 dan Gambar 2.

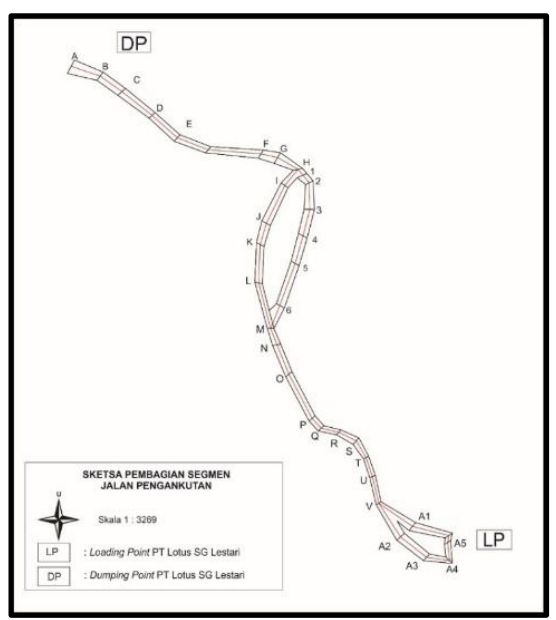

Gambar 1. Sketsa Segmen Jalan Tambang

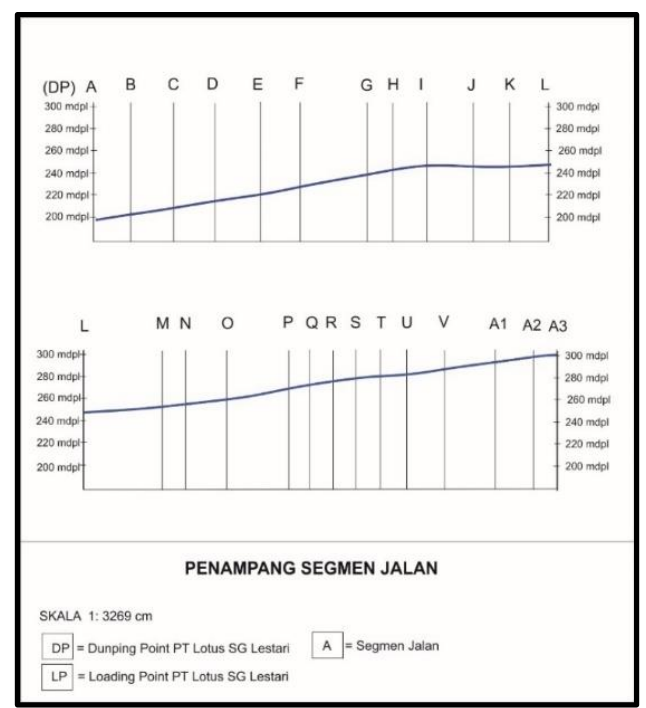

Gambar 2. Sketsa Segmen Jalan Tambang

\section{Lebar Jalan Angkut}

Lebar jalan tambang yang digunakan pada daerah penelitian dari loading point menuju hopper terdiri dari beberapa segmen satu jalur dan dua jalur. Berdasarkan hasil perhitungan untuk standar lebar jalan satu jalur didapatkan 6,40 meter dan dua jalur selebar 11,20 meter. Hasil pengukuran lebar jalan angkut dalam keadaan lurus dari loading point ke hopper dapat dilihat pada Tabel 1.

Tabel 1. Lebar Jalan Angkut Kondisi Lurus 


\begin{tabular}{|c|c|c|c|c|c|}
\hline \multicolumn{3}{|c|}{ Segmen } & \multirow{2}{*}{$\begin{array}{c}\begin{array}{c}\text { Rencana } \\
\text { Berdasarkan } \\
\text { Perhitungan (m) }\end{array} \\
11,20\end{array}$} & \multirow{2}{*}{$\begin{array}{r}\begin{array}{c}\text { Lebar Jalan } \\
\text { Lurus } \\
\text { Aktual (m) }\end{array} \\
21,60\end{array}$} & \multirow{2}{*}{$\begin{array}{c}\text { Penambahan } \\
\text { Lebar Jalan } \\
\text { (m) }\end{array}$} \\
\hline A & - & B & & & \\
\hline B & - & $\mathrm{C}$ & 11,20 & 14,53 & - \\
\hline $\mathrm{C}$ & - & D & 11,20 & 14,62 & - \\
\hline D & - & E & 11,20 & 11,30 & - \\
\hline E & - & F & 11,20 & 12,15 & - \\
\hline F & - & G & 11,20 & 11,43 & - \\
\hline $\mathrm{H}$ & & I & 11,20 & 12,17 & - \\
\hline I & - & $\mathrm{J}$ & 6,40 & 13,63 & - \\
\hline $\mathrm{J}$ & - & K & 6,40 & 11,86 & - \\
\hline K & - & $\mathrm{L}$ & 6,40 & 13,74 & - \\
\hline $\mathrm{L}$ & - & $\mathrm{M}$ & 11,20 & 11,92 & - \\
\hline M & - & $\mathrm{N}$ & 11,20 & 10,25 & 0,95 \\
\hline $\mathrm{N}$ & - & $\mathrm{O}$ & 11,20 & 9,32 & 1,88 \\
\hline $\mathrm{O}$ & - & P & 11,20 & 11,42 & - \\
\hline $\mathrm{P}$ & - & $\mathrm{Q}$ & 11,20 & 11,21 & - \\
\hline Q & - & $\mathrm{R}$ & 11,20 & 10,94 & 0,26 \\
\hline $\mathrm{R}$ & - & S & 11,20 & 9,12 & 2,08 \\
\hline$S$ & - & $\mathrm{T}$ & 11,20 & 12,33 & - \\
\hline $\mathrm{T}$ & - & $\mathrm{U}$ & 11,20 & 8,12 & 3,08 \\
\hline $\mathrm{U}$ & - & V & 11,20 & 8,48 & 2,72 \\
\hline V & - & A2 & 6,40 & 14,72 & - \\
\hline A2 & - & A3 & 6,40 & 12,73 & - \\
\hline A3 & & A4 & 6,40 & 12,54 & - \\
\hline A4 & - & A5 & 6,40 & 10,76 & - \\
\hline A5 & & A1 & 6,40 & 12,21 & - \\
\hline $\mathrm{H}$ & - & 1 & 6,40 & 15,28 & - \\
\hline 1 & - & 2 & 6,40 & 15,18 & - \\
\hline 2 & - & 3 & 6,40 & 14,65 & \\
\hline 3 & - & 4 & 6,40 & 14,16 & \\
\hline
\end{tabular}




\begin{tabular}{rrrrrr}
\hline & Segmen & & \multicolumn{1}{c}{$\begin{array}{c}\text { Rencana } \\
\text { Berdasarkan } \\
\text { Perhitungan }(\mathbf{m})\end{array}$} & $\begin{array}{c}\text { Lebar Jalan } \\
\text { Lurus } \\
\text { Aktual (m) }\end{array}$ & $\begin{array}{c}\text { Penambahan } \\
\text { Lebar Jalan } \\
(\mathbf{m})\end{array}$ \\
\hline 4 & - & 5 & 6,40 & 12,93 & - \\
5 & - & 6 & 6,40 & 12,95 & - \\
$\mathrm{G}$ & - & $\mathrm{H}$ & 11,20 & 17,94 & - \\
\hline
\end{tabular}

Lebar jalan angkut pada tikungan selalu dibuat lebih besar dari pada jalan lurus. Hal ini dimaksudkan untuk mengantisipasi adanya penyimpangan lebar alat angkut yang disebabkan oleh sudut yang dibentuk oleh roda depan dengan badan truk saat melintasi tikungan. Berdasarkan hasil perhitungan AASHTO lebar jalan kondisi tikungan minimal untuk satu jalur yaitu 10,6 meter dan dua jalur selebar 18,6 meter, hasil pengukuran dari loading point ke hopper dapat dilihat pada Tabel 2 .

Tabel 2. Lebar Jalan Angkut Kondisi Tikungan

\begin{tabular}{crrr}
\hline Segmen & $\begin{array}{c}\text { Rencana } \\
\text { Berdasarkan } \\
\text { Perhitungan } \\
(\mathbf{m})\end{array}$ & $\begin{array}{c}\text { Lebar Jalan } \\
\text { Tikungan } \\
\text { Aktual (m) }\end{array}$ & $\begin{array}{c}\text { Penambahan Lebar } \\
\text { Jalan (m) }\end{array}$ \\
\hline $\mathrm{H}$ & 18,6 & 17,94 & 0,66 \\
$\mathrm{Q}$ & 18,6 & 11,21 & 7,66 \\
$\mathrm{~S}$ & 18,6 & 9,12 & 6,27 \\
$\mathrm{~A} 4$ & 10,6 & 10,76 & - \\
2 & 10,6 & 15,18 & 6,68 \\
$\mathrm{M}$ & 18,6 & 11,92 & \\
\hline
\end{tabular}

\section{Kemiringan Jalan (Grade)}

Kemiringan jalan angkut pada kegiatan pertambangan dinyatakan dalam satuan persen (\%). Berdasarkan standar Kepmen No. 1827/K/30/MEM/2018 maksimal kemiringan jalan maksimal sebesar $12 \%$, dari hasil pengukuran didapatkan 25 segmen jalan tambang yang tidak sesuai dengan standar sehingga diperlukan pengurangan beda tinggi pada segmen tersebut. Untuk hasil pengukuran kemiringan jalan dapat dilihat pada Tabel 3.

Tabel 3. Kemiringan Jalan (Grade) Setiap Segmen

\begin{tabular}{rrrrrrr}
\hline Segmen & $\begin{array}{c}\text { Beda Tinggi } \\
(\mathbf{m})\end{array}$ & $\begin{array}{c}\text { Panjang Jalan } \\
(\mathbf{m})\end{array}$ & $\begin{array}{c}\text { Grade Aktual } \\
(\boldsymbol{\%})\end{array}$ & $\begin{array}{c}\text { Grade Standar } \\
(\boldsymbol{\%})\end{array}$ & $\begin{array}{c}\text { Pengurang } \\
\text { an Beda } \\
\text { Tinggi (m) }\end{array}$ \\
\hline $\mathrm{B}-\mathrm{C}$ & 8,78 & 38,01 & 23,09 & 12,00 & 4,21 \\
$\mathrm{C}-\mathrm{D}$ & 8,68 & 54,82 & 15,84 & 12,00 & 2,10 \\
$\mathrm{D}-\mathrm{E}$ & 13,81 & 48,17 & 28,67 & 12,00 & 8,03 \\
$\mathrm{E}-\mathrm{F}$ & 10,03 & 47,17 & 21,26 & 12,00 & 4,37 \\
F $-\mathrm{G}$ & 23,00 & 75,24 & 30,57 & 12,00 & 13,97
\end{tabular}




\begin{tabular}{|c|c|c|c|c|c|c|}
\hline G & $-\quad \mathrm{H}$ & 7,97 & 24,52 & 32,49 & 12,00 & 5,02 \\
\hline $\mathrm{H}$ & I & 15,83 & 41,23 & 38,39 & 12,00 & 10,88 \\
\hline I & $-\quad J$ & 20,64 & 59,93 & 34,43 & 12,00 & 13,44 \\
\hline $\mathrm{J}$ & $-\quad K$ & 8,39 & 31,32 & 26,79 & 12,00 & 4,63 \\
\hline $\mathrm{K}$ & - L & 17,88 & 55,04 & 32,49 & 12,00 & 11,28 \\
\hline $\mathrm{L}$ & $-\quad M$ & 10,57 & 75,24 & 14,05 & 12,00 & 1,55 \\
\hline M & $-\quad N$ & 4,35 & 24,70 & 17,63 & 12,00 & 1,39 \\
\hline $\mathrm{N}$ & $\mathrm{O}$ & 8,81 & 45,31 & 19,44 & 12,00 & 3,37 \\
\hline $\mathrm{O}$ & $\mathrm{P}$ & 17,73 & 71,12 & 24,93 & 12,00 & 9,20 \\
\hline $\mathrm{P}$ & Q & 6,58 & 19,10 & 34,43 & 12,00 & 4,29 \\
\hline Q & $\mathrm{R}$ & 7,86 & 25,71 & 30,57 & 12,00 & 4,78 \\
\hline $\mathrm{R}$ & $-\quad S$ & 3,90 & 27,73 & 14,05 & 12,00 & 0,57 \\
\hline$S$ & $\mathrm{~T}$ & 4,90 & 27,78 & 17,63 & 12,00 & 1,57 \\
\hline $\mathrm{T}$ & $\mathrm{U}$ & 5,53 & 28,46 & 19,44 & 12,00 & 2,12 \\
\hline $\mathrm{U}$ & V & 6,19 & 39,05 & 15,84 & 12,00 & 1,50 \\
\hline $\mathrm{H}$ & 1 & 9,64 & 33,62 & 28,67 & 12,00 & 5,61 \\
\hline 1 & -2 & 6,66 & 24,84 & 26,79 & 12,00 & 3,67 \\
\hline 2 & 3 & 6,02 & 38,01 & 15,84 & 12,00 & 1,46 \\
\hline 3 & 4 & 12,01 & 39,29 & 30,57 & 12,00 & 7,30 \\
\hline 4 & 5 & 5,69 & 40,52 & 14,05 & 12,00 & 0,83 \\
\hline 5 & -6 & 18,32 & 63,91 & 28,67 & 12,00 & 10,66 \\
\hline
\end{tabular}

\section{Jari - jari Tikungan}

Jari - jari tikungan dilakukan dengan cara penggambaran lingkaran pada awal tikungan hingga akhir tikungan untuk setiap segmen jalan, dari hasil perhitungan didapatkan lebar jari - jari tikungan minimal sebesar 13,17 meter dengan kecepatan maksimum $20 \mathrm{~km} / \mathrm{jam}$ sehingga terdapat satu segmen jalan yang perlu dilakukan perbaikan dengan menambah jari - jari tikungan yaitu segmen A4. Hasil perhitungan jari - jari tikungan dapat dilihat pada Tabel 4.

Tabel 4. Jari-Jari Tikungan

\begin{tabular}{cccc}
\hline Segmen & $\begin{array}{c}\text { Jari - jari Aktual } \\
(\mathbf{m})\end{array}$ & $\begin{array}{c}\text { Jari - jari minimal } \\
\text { Rekomendasi (m) }\end{array}$ & $\begin{array}{c}\text { Penambahan Jari - } \\
\text { jari tikungan (m) }\end{array}$ \\
\hline $\mathrm{H}$ & 14,28 & 13,17 & - \\
$\mathrm{Q}$ & 19,24 & 13,17 & - \\
$\mathrm{S}$ & 28,62 & 13,17 & - \\
\hline
\end{tabular}




\begin{tabular}{cccc}
\hline A4 & 10,35 & 13,17 & 2,82 \\
2 & 21,04 & 13,17 & - \\
M & 14,31 & 13,17 & - \\
\hline
\end{tabular}

\section{Superelevasi}

Superelevasi dibuat dengan tujuan untuk memaksimalkan kecepatan kendaraan dalam mengatasi tikungan. Penentuan superelevasi maksimum berdasarkan penentuan jari-jari tikungan, dimana didapatkan nilai superelevasi maksimum sebesar 6\%, hal tersebut didasari atas standar kecepatan laju kendaraan di perusahaan pada tikungan yaitu $20 \mathrm{~km} / \mathrm{jam}$.

Tabel 5. Superelevasi

\begin{tabular}{cccccc}
\hline Segmen & $\begin{array}{c}\text { Lebar } \\
\text { Jalan } \\
\text { Tikungan } \\
\text { Aktual } \\
(\mathbf{m})\end{array}$ & $\begin{array}{c}\text { Superelevasi } \\
\text { Aktual (\%) }\end{array}$ & $\begin{array}{c}\text { Beda } \\
\text { Tinggi } \\
\text { Aktual } \\
(\mathbf{m})\end{array}$ & $\begin{array}{c}\text { Superelevasi } \\
\text { Rekomendasi } \\
(\%)\end{array}$ & $\begin{array}{c}\text { Penambahan } \\
\text { Beda Tinggi } \\
(\mathbf{m})\end{array}$ \\
\hline $\mathrm{H}$ & 17,94 & $3,49 \%$ & 0,63 & $6,00 \%$ & 1,113 \\
$\mathrm{Q}$ & 10,94 & $1,75 \%$ & 0,19 & $6,00 \%$ & 1,113 \\
$\mathrm{~S}$ & 12,33 & $2,62 \%$ & 0,32 & $6,00 \%$ & 1,113 \\
$\mathrm{~A} 4$ & 10,76 & $1,75 \%$ & 0,19 & $6,00 \%$ & 0,634 \\
2 & 15,18 & $3,49 \%$ & 0,53 & $6,00 \%$ & 0,634 \\
$\mathrm{M}$ & 11,92 & $1,75 \%$ & 0,21 & $6,00 \%$ & 1,113 \\
\hline
\end{tabular}

\section{Kemiringan Melintang (Cross Slope)}

Pengukuran kemiringan melintang ini dilakukan dengan mengukur kemiringan dari tengah jalan ke tepi jalan yang dinyatakan dalam satuan $(\mathrm{mm} / \mathrm{m})$. Berdasarkan dari hasil pengukuran di daerah penelitian tidak terdapat kemiringan melintang, sehingga perlu adanya rekomendasi untuk pembuatan kemiringan melintang dengan penambahan beda tinggi pada setiap segmen dari area loading point ke hopper berkisar dari 0,1280-0,2240 meter.

\section{Perhitungan Rimpull}

Berdasarkan hasil perhitungan rimpull pada alat angkut Dump Truck Tonly TL-855BR sudah memenuhi kebutuhan rimpull dalam mengatasi kondisi jalan angkut, sehingga saat alat berjalan dapat optimal. Untuk rimpull setiap gear pada alat Dump Truck Tonly $T L-855 B R$ dapat dilihat pada Tabel 6.

Tabel 6. Rimpull Tonly $T L-855 B R$

\begin{tabular}{cccccc}
\hline Gear & $\begin{array}{c}\text { Kecepatan } \\
(\mathbf{m p h})\end{array}$ & $\begin{array}{c}\text { Kecepatan } \\
(\mathbf{k m} / \mathbf{j a m})\end{array}$ & $\begin{array}{c}\text { Efesiensi } \\
\text { mesin }\end{array}$ & HP & $\begin{array}{c}\text { Rimpull } \\
(\mathbf{l b})\end{array}$ \\
\hline 1 & 5,359 & 9 & $85 \%$ & 375 & 22.304 \\
2 & 7,309 & 12 & $85 \%$ & 375 & 16.354 \\
3 & 10,097 & 16 & $85 \%$ & 375 & 11.838 \\
\hline
\end{tabular}




\begin{tabular}{llllll}
\hline 4 & 13,602 & 22 & $85 \%$ & 375 & 8.787 \\
5 & 18,479 & 30 & $85 \%$ & 375 & 6.468 \\
6 & 30,416 & 49 & $85 \%$ & 375 & 3.930 \\
7 & 48,970 & 79 & $85 \%$ & 375 & 2.441 \\
\hline
\end{tabular}

Perhitungan rimpull pada setiap segmen jalan tambang pada kondisi alat angkut membawa beban dan kondisi beban kosong dibandingkan dengan rimpull setiap gear. Berdasarkan hasil perhitungan dengan mengoptimalkan kecepatan dari alat dapat mempercepat waktu edar (cycle time) dari alat angkut yang semakin cepat, sehingga terdapat perubahan dari kondisi waktu edar (cycle time) aktual dengan waktu edar (cycle time) berdasarkan rimpull, kondisi jalan angkut tambang sangat berpengaruh terhadap waktu edar alat angkut yang nantinya waktu edar alat angkut tersebut dapat berpengaruh terhadap produksi. Untuk perbandingan waktu edar (cycle time) dari alat angkut dapat dilihat pada Tabel 7.

Tabel 7. Perbandingan Waktu Edar (Cycle Time)

\begin{tabular}{ccr}
\hline No & Keterangan & Cycle Time (Menit) \\
\hline 1 & Berdasarkan Kecepatan Aktual & 14,42 \\
2 & Berdasarkan Kecepatan Rimpull & 12,76 \\
\hline & Perbedaan & 1,66 \\
\hline
\end{tabular}

\section{Kesimpulan}

Geometri jalan tambang aktual dari front kerja yang berada di bench 9 hingga hopper diketahui bahwa masih ada beberapa segmen jalan yang belum sesuai berdasarkan teori AASHTO dan Kepmen No. 1827/K/30/MEM/2018 mulai dari kemiringan jalan, lebar jalan dengan kondisi lurus, lebar jalan dengan kondisi tikungan, kemiringan melintang (Cross Slope) dan juga superelevasi. Terdapat upaya perbaikan yang dilakukan untuk meningkatkan produksi diantaranya adalah memperlebar jalan angkut, menurunkan kemiringan jalan atau grade agar alat angkut agar dapat memaksimalkan kecepatan alat angkut, memperbaiki jari-jari tikungan, superelevasi, kemiringan melintang (Cross slope), sehingga cycle time dapat lebih cepat dan produksi akan semakin meningkat.

\section{Acknowledge}

1. Dosen dan Staff Prodi Teknik Pertambangan Universitas Islam Bandung. kepada Bapak Dr. Ir. Yunus Ashari, M.T. selaku Ketua Prodi, Bapak Noor Fauzi Isniarno, S.Si.,S.Pd., M.T. selaku Sekretaris Prodi, Bapak Ir. Yuliadi, S.T, M.T. selaku Pembimbing sekaligus wali dosen, Bapak Zaenal, Ir., M.T. selaku Co-Pembimbing serta semua Dosen dan Staf yang senantisa memberikan do'a, dukungan, motivasi kepada penyusun.

2. Orang Tua dan Keluarga Penulis, Kedua Orangtua, Rice Noviati dan Dadang Djuhara, terimakasih selalu memberikan dukungan terbaik. Terimakasih kepada Sri Zahra Mina telah memberikan dukungan dan motivasi kepada penulis.

3. Perusahaan Penelitian, terimakasih kepada PT XYZ yang sudah memberikan kesempatan penulis untuk melaksanakan penelitian.

4. Keluarga Besar Tambang 2017, terimakasih telah menjadi keluarga dan tidak pernah lelah membantu dan berjuang bersama serta support terbaik yang diberikan. 


\section{Daftar Pustaka}

[1] Anonim, 1993, “AASHTO Guide for Design of Pavement Structures - Volume I', Washington DC.

[2] Anonim, 2018, "Keputusan Menteri Energi dan Sumber Daya Mineral (ESDM) Republik Indonesia Nomor 1827/K/30/MEM/2018 Tentang Pedoman Pelaksanaan Kaidah Teknik Pertambangan yang Baik", Menteri Energi Sumber Daya Mineral Republik Indonesia.

[3] Airindo, 2017, "TL855BR Brochure" PT Airindo Sakti, Jakarta, Indonesia.

[4] Azwari, Rudi, 2015, "Evaluasi Jalan Angkut dari Front Tambang Batubara menuju Stockpile Block B pada Penambangan Batubara di PT. Minemex Indonesia, Desa Talang Serdang Kecamatan Mandiangin Kabupaten Sarolangun Provinsi Jambi”. Bandung: Prodi Teknik Pertambangan, Universitas Islam Bandung.

[5]Fast Gear, 2018, "Fast Transmission 7DS180” Shaanxi Fast Gear, China

[6] Kobelco Construction Machinery, 2021 "Spesifikasi Kobelco SK-330" Southeast Asia.

[7] Maulana, Subhan Bram et al, 2018, "Evaluasi Kondisi Jalan Angkut dari Front Penambangan Menuju Rom Stockpile untuk Mencapai Target Produksi 15.000 Ton Batubara Perbulan PT. Prima Dito Nusantara Jobsite KBB Kabupaten Sarolangun, Provinsi Jambi”. Padang: Jurusan Teknik Pertambangan, Universitas Negeri Padang

[8] Prodjosumarto, Partanto, 1993, "Pemindahan Tanah Mekanis", Jurusan Teknik Pertambangan, Fakultas Teknologi Mineral, Institut Teknologi Bandung, Bandung.

[9] Suwandhi Awang, 2004, "Perencanaan Jalan Tambang", Diklat Perencanaan Tambang Terbuka, Universitas Islam Bandung.

[10] Sari, Avellyn Shinthya et al, 2020, "Kajian Teknis Analisis Resiko Jalan Tambang Batubara PT Pasir Walannae, Kabupaten Bone, Provinsi Sulawesi Selatan". Surabaya: Jurusan Teknik Pertambangan, Universitas Teknologi Adhi Tama. 